\title{
Research on the Application of Cross-Specialty Education and Situational Simulation Teaching in Operation Nursing Practice Teaching
}

\author{
Fangyin Liu ${ }^{1 \#}$, Liuyue Wang ${ }^{1 \#}$, Jingjie Zhao ${ }^{1 \#}$, Liucui Chen ${ }^{1}$, Xialu Zhang ${ }^{1}$, Chaoling Ling ${ }^{1}$, Guiling Shi ${ }^{1}$, Qiujiao Liao ${ }^{1}$, \\ Liuzhi Wei ${ }^{2}$, Zechen Wang ${ }^{2}$, Qiuju Wei ${ }^{2}$, Jihua Wei ${ }^{{ }^{*}}$, Lingzhang Meng ${ }^{2 *}$, Qunqiang Luo ${ }^{{ }^{*}}$ \\ ${ }^{1}$ Affiliated Hospital of Youjiang Medical Uniwersity for Nationalities, Baise, Guangxi Province, China, 533000 \\ ${ }^{2}$ Youjiang Medical Uniwersity for Nationalities, Baise, Guangxi Province, China, 533000 \\ "These authors contributed equally to this study \\ Correspondence: Qunqiang Luo, Affiliated Hospital of Youjiang Medical Uniwersity for Nationalities, Baise, Guangxi \\ Province, 533000, China;
}

Lingzhang Meng, Youjiang Medical Uniwersity for Nationalities, Baise, Guangxi Province, China, 533000, China; Jihua Wei, Affiliated Hospital of Youjiang Medical Uniwersity for Nationalities, Baise, Guangxi Province, 533000, China.

Received: June 6, 2021

Accepted: June 25, 2021

Online Published: June 26, 2021

doi:10.11114/jets.v9i6.5274

URL: https://doi.org/10.11114/jets.v9i6.5274

\begin{abstract}
Objective To examine the practical effect of inter-professional education and situational simulation teaching implemented in surgical nursing practice teaching. Methods On the whole, 100 undergraduate nursing students in the operating room of the hospital of the authors from May 2019 to August 2020 were selected. These students fell to two groups with the random number table method. The control received the regular teaching, and the research group were given the interprofessional education and context. The Simulation teaching was conducted to compare the theoretical knowledge, skill level, various abilities of the two groups of students, as well as the satisfaction of the operating room doctors to the nursing cooperation of the interns. Results The research group achieved higher theoretical knowledge and a higher skill level than the control $(p<0.05)$; the various abilities of the research group were higher than those of the control $(p<0.05)$; the operating room doctors of the research group were more satisfied with the nursing cooperation of interns, as compared with those of the control $(p<0.05)$. Conclusion In the surgical nursing practice teaching, the inter-professional education and the situational simulation teaching have significant effects and are worth clinical applications.
\end{abstract}

Keywords: cross-professional education; situation simulation teaching; surgical nursing practice teaching; theoretical knowledge; skill levels

\section{Background}

Operating room nursing refers to a profession with strong practicality. Unlike other clinical environments, operating room raises higher requirements for asepsis, and it can involve more complex working processes. As novel instruments and equipment have been leaping forward, a greater difficulty for learning and more pressure are imposed on practice nursing students (Zhan et al., 2019). How to improve students' learning ability and practice ability and alleviate their learning pressure in clinical teaching is recognized as a problem that should be addressed clinically. Conventional teaching methods are difficult for students to understand, resulting in students' superficial memory of knowledge. Most students just memorize knowledge by rote, so the teaching content cannot be applied flexibly by students. Cross-professional education and situational simulation teaching are capable of vividly displaying the teaching content, which is more conducive to the learning of operating room nursing students and contributes their application ability and practical ability (Guo et al., 2018). Cross-specialty education and situational simulation teaching are considered a novel teaching method of problem, which involves oriented teaching, heuristic teaching and experiential teaching. Conventional medical teaching rarely considers students' ability to cooperate in practical scenarios, so a better teaching method should be urgently developed (Banks et al., 2019). In the practice teaching of surgical nursing in the authors' hospital, cross-professional education and situational simulation teaching are adopted to carry out teaching with remarkable effects. The research is presented as follows. 


\section{Materials and Methods}

\subsection{General Materials}

On the whole, 100 undergraduate nursing interns in the operating room of the authors' hospital from May 2019 to August 2020 were selected, which fell to two groups with the random number table method. Inclusion criteria: (1) students all practicing nursing in the operating room of the authors' hospital; (2) physical and mental health; (3) all informed of the study. Exclusion criteria: (1) disagree with the study; (2) having received relevant knowledge training. In the control, there were 50 patients, 1 male and 49 females, aged 20-23 years, with an average age of (21.5 \pm 0.5$)$ years old. The study group comprised 50 patients, 2 males and 48 females, aged 21-23 years, with an average age of (22.0 \pm 0.6$)$ years. No difference was identified between the two groups $(p>0.05)$, and the study was approved and conducted under their supervision.

\subsection{Methods}

1.2.1 Control: The control received the regular teaching, which mainly included the following. (1) One Belt One Teaching, and students studied with the teacher throughout the internship. (2) On the first day of teaching, the chief teacher would train students with relevant knowledge of the subject, introduce the operating room working environment, nursing characteristics, teachers' responsibilities, responsibilities of each class, internship requirements and professional characteristics, and help students gain insights into the learning objectives, assessment time, methods and requirements. (3) From the second day of teaching, I learned the theories and skills related to the operating room with the teacher, and participated in the itinerant or instrument nurse work as guided by the teacher.

\subsubsection{The Research Groups}

The research group conducted the cross-professional education and situation simulation teaching, which largely included the following. (1) Operation simulation scenes: the simulation operating room of the clinical skills training center was equipped with several facilities (e.g., operating room, instrument preparation room, sterile goods storage room, sewage disposal room and surgical toilet). Given the clinical work scenes, the operating room was equipped with a tray for operation, a vehicle for surgical instruments, a disinfectant for operation, a shadowless lamp and a multi-functional operating bed, etc. The dressing package and the instrument package were placed on the surgical instrument cart for the subsequent use. (2) Setting up of teaching groups: Each group consisted of 1 nursing teacher, 1 clinician and 1 anesthesiologist responsible for teaching demonstration. (3) Development across the professional education of medical surgery: The simulation teaching program was processed from a patient's home receiving inspections, the intravenous shop, anesthesia, disinfection, wipes, surgery process were established till the end of surgery patients with the ward handover process all the time of surgery (e.g., teaching contents and requirements). Moreover, different roles were designed, and the teaching effect evaluation and assessment standard was set. (4) Teaching process: Week 1: (1) enrollment education; (2) take multimedia as the way, show the operation video involved in the teaching to the students via videos; (3) to observe the operation cooperation of the medical team, to observe the work content of the roving nurses, hand washing nurses, anesthetists and surgeons during the whole operation from entering the operating room to leaving the operating room; (4) in the simulated operating room of the training center, students practiced surgical hand washing, wearing sterile operating clothes, wearing sterile gloves, auxiliary towels, etc.; (5) A simulation scenario was established in which students were asked to review related theoretical operations, with 3 $\sim 4$ residents and two nurses trained as a group performing the roles of surgeon, anesthesiologist, nurse instrument, and visiting nurse, cooperating to complete the operation. All students' operational, communication and cooperation skills were practiced in simulated situations; (6) students combined their own professional experience of surgery (advantages and disadvantages) with the teacher comment guidance; each group of students was cruelly required to complete assignments 1 critical reflection.

A brief description and discussion were given of the process by which the assessment team provided surgical services, and the lessons learned were shared, as well as how this process affects their future practice. Thus, the safety practice, communication skills and teamwork ability of medical interns could be trained. Week $2 \sim$ Week 4 : Students entered the operating room to participate in the operation cooperation, and returned to the training center to simulate the operating room every Friday. Each time, according to different cases, students conducted medical and surgical cooperation, summarized and analyzed the cooperation effect, and accepted the teacher's comments and guidance.

\subsection{Observation Indicators}

(1) The independent learning ability evaluation scale and the learning motivation measurement scale were adopted to assess their independent learning ability and learning motivation. The scale for evaluating autonomous learning ability included 34 items in four dimensions (e.g., self-motivated belief, task analysis, self-monitoring and adjustment, and self-evaluation). Each dimension adopted the scoring method of 1 to 5 points. The total score of the scale was the sum 
of the scores of each dimension, and the score was between 34 and 170 points. Cronbach's $\alpha$ coefficient of the scale was 0.94, which suggested that the scale had good reliability and validity. Dynamic measurement scale included learning motivation, learning interest, learning needs, learning attitude, learning motivation, and it inspired and maintained individual learning activity five dimensions of a total of 32 items, each dimension $1 \sim 5$ points score method. The scale total score was the sum of each dimension score, scoring between 32-160 points, pointing the point the higher the power level(Zhu et al., 2018).Cronbach's $\alpha$ coefficient of the scale was 0.87 , which suggested that the scale had high reliability and validity. (2) The theoretical knowledge of the two groups of students was compared. Moreover, the teaching teacher marked the skill level of the students. The full score of each item was 100, and the higher the score, the better it would be. (3) The satisfaction of operating room doctors to the nursing cooperation of interns was compared between the two groups, satisfaction (> 90\%), basic satisfaction (70\%-90\%) and dissatisfaction $(<70 \%)$ (Lindsay et al., 2018). In this study, satisfaction indicates a score $\geq 136$, basic satisfaction indicates a score ranging from 102 to 135 , and dissatisfaction indicates a score $<102$.

\subsection{Statistical Methods}

SPSS20.0 software was adopted to express the measured data as. The repeated measure analysis of variance was conducted for intra-group comparison, and $p<0.05$ represented difference.

\section{Results}

\subsection{Comparison of Theoretical Knowledge and Skills of Students in the Two Groups}

The theoretical knowledge and skills of the research group were higher than those of the control $(p<0.05)$, as listed in Table 1.

Table 1. Comparison of theoretical knowledge and skills (points, $\mathrm{x} \pm \mathrm{s}$ )

\begin{tabular}{cccc}
\hline Group & Number of cases & Theoretical knowledge & Skill levels \\
\hline Control & 50 & $83.43 \pm 5.62$ & $82.58 \pm 4.41$ \\
Research group & 50 & $93.20 \pm 4.48$ & $92.40 \pm 4.04$ \\
T & $/$ & -9.616 & -11.605 \\
P & $/$ & 0.001 & 0.001 \\
\hline
\end{tabular}

\subsection{Comparison of Students' Abilities Between the Two Groups}

The abilities of the study group were higher than those of the control $(p<0.05)$, as shown in Table 2 .

Table 2. Comparison of abilities (points, $\mathrm{x} \pm \mathrm{s}$ )

\begin{tabular}{cccc}
\hline Group & Number of cases & Self-learning ability & Learning motivation \\
\hline Control & 50 & $109.42 \pm 13.73$ & $104.28 \pm 8.47$ \\
Research group & 50 & $133.86 \pm 17.21$ & $122.12 \pm 10.99$ \\
$\mathrm{~T}$ & $/$ & -7.850 & -9.092 \\
$\mathrm{P}$ & $/$ & 0.001 & 0.001
\end{tabular}

3.3 Comparison of Satisfaction With the Nursing Cooperation Between the Two Groups of Operating Room Doctors on Interns

The satisfaction with the nursing cooperation between the operating room doctors in the research group was higher than that in the control $(p<0.05)$, as shown in Table 3 . 
Table 3. Comparison of satisfaction of operating room doctors on nursing cooperation of interns (example, \%)

\begin{tabular}{cccccc}
\hline Group & $\begin{array}{c}\text { Number of } \\
\text { cases }\end{array}$ & satisfaction & $\begin{array}{c}\text { Basically } \\
\text { satisfied }\end{array}$ & Dissatisfied & Satisfaction rate \\
\hline $\begin{array}{c}\text { Control } \\
\text { Research } \\
\text { group }\end{array}$ & 50 & $15(30.0)$ & $27(54.0)$ & $8(16.0)$ & $84.0 \%$ \\
$\mathrm{X}^{2}$ & 50 & $26(52.0)$ & $22(44.0)$ & $2(4.0)$ & $96.0 \%$ \\
$\mathrm{P}$ & $/$ & $/$ & $/$ & $/$ & 7.061 \\
\hline
\end{tabular}

\section{Discuss}

\subsection{Interdisciplinary Education and Situational Simulation Teaching Can Improve Students' Theoretical Knowledge and Skills}

Operating room refers to a vital place for clinical rescue of patients, which is inconsistent with other clinical places, with higher requirements on aseptic environment and skills of medical staff. With the increasing number of clinical nursing interns, it is very important to master nursing skills through effective teaching methods. Cross-professional education and situational simulation teaching are novel teaching methods proposed by medical education experts over the past few years, which mainly involve the cooperation and learning between two different professional learners (Wei et al., 2018). With traditional teaching methods as the syllabus of knowledge, teachers assist students in experiments and practices to promote students' learning and absorption of knowledge. However, the traditional teaching method is one of indoctrination. Students are in a passive state, understanding and learning the connotation of knowledge is not deep. Therefore, it is easy to take seriously, but the teaching effect is still not significant. Especially for the nursing in the operating room, the operation in this place plays an important role in the safety of patients' lives, and also affects whether the operation can be carried out smoothly (Zhang et al., 2018).For instance, contamination of surgical instruments or surgical areas due to lax notions of sterility during surgery is a risk of postoperative infection. Accordingly, effective cooperation between doctors and nursing staff is required during the operation to accurately grasp the operating room situation, thereby reducing errors, promoting the smooth operation and ensuring the treatment effect. Across the professional education and situation belongs to the interactive teaching, simulation teaching in teaching during the fully mobilize students' learning enthusiasm, initiative, can prompt students to learn knowledge to deep understanding and the understanding, creating the simulation at the same time, can let students feel the operating room environment and working condition, it is more advantageous to improve the students' practical ability. Finally, it is beneficial to improve the teaching effect. After simulating the real situation during the teaching period, students can play different roles to learn, so that they can have a deep understanding of the knowledge, and then mobilize their enthusiasm to integrate, absorb and utilize the required knowledge(Cook et al., 2019). Such a teaching method has been extensively employed in nursing teaching, and it can effectively make up for the deficiency of conventional teaching methods. Studies have shown that cross-major education and situational simulation teaching can significantly improve students' cooperation ability and improve clinical medical quality(Johnson et al., 2017). As revealed from the research results, the theoretical knowledge and skills of the research group are higher than those of the control $(p<0.05)$, which indicates that in the practice teaching of surgical nursing, cross-professional education and situational simulation teaching have a significant effect, thereby enabling students to have a more detailed and full understanding of surgical nursing knowledge. Moreover, it shows that cross-disciplinary education and situational simulation teaching can significantly improve the level of students' theoretical knowledge and skills.

\subsection{Cross-Professional Education and Situational Simulation Teaching Can Improve Students' Abilities}

The results showed that the abilities of the study group were higher than those of the control $(p<0.05)$, which indicated that in surgical nursing practice teaching, cross-professional education and situational simulation teaching were more conducive to improving students' abilities. Cross-professional education and situational simulation teaching play an important role in nursing teaching, and the application of this method in clinical nursing teaching can enable students to master more medical knowledge on the basis of the original, improve students' knowledge in a wide range of aspects, and deepen their knowledge of nursing(Jennifer et al., 2018). Next, the operation in the operating room requires the good cooperation of medical staff, and the effective integration of this method into nursing teaching can significantly improve the cooperation degree and cooperation ability of medical staff. Moreover, cross-major education and situational simulation teaching are different from conventional teaching methods. As guided by the novel method, students' learning enthusiasm is significantly improved, changing from the previous passive state to the active state, so that they can better master and use the learned knowledge (Lei et al., 2020). 


\subsection{Cross-Professional Education and Situational Simulation Teaching Can Improve Surgeons' Satisfaction With the} Nursing Cooperation of Interns

As suggested from the results, the degree of satisfaction of the operating room doctors in the research group to the nursing cooperation of the interns was higher than that in the control $(p<0.05)$, which demonstrated that in the surgical nursing practice teaching, cross-professional education and situational simulation teaching were more conducive to improving the satisfaction of the operating room doctors to the nursing interns. This is because cross-professional education and situational simulation teaching can effectively improve the cooperation between medical staff, reduce errors, ensure the safety of surgery, speed up the smooth operation, and finally achieve a better surgical effect(Li-Mei et al., 2019). Conventional operating room nursing teaching methods are usually a pair of teaching. The survey showed that although $66.7 \%$ of the teaching teachers to students to explain the operation of nursing knowledge in detail, but the content of the nursing results of surgery is more important, the content is more complex, stricter, the time is very short. As a result, students' learning pressure is greater, and many students' learning interest and confidence are significantly reduced. Therefore, the traditional methods cannot well meet the current clinical needs, which is not conducive to students' knowledge and understanding of nursing (Johnson et al., 2017). In addition, conventional methods cannot effectively improve the cooperation ability between medical staff, and it is difficult to create a communication environment for them. Thus, various errors can occur during the cooperation, thereby reducing the quality of surgery, so the satisfaction of doctors and patients is lower. Cross-professional education and situational simulation teaching can significantly improve the cooperation ability of medical staff.

\section{Conclusion}

In the practice teaching of surgical nursing, cross-professional education and situational simulation teaching can exert significant contributing effects, and they are worth applying clinically.

\section{Conflicts of Interest}

The authors declare no conflicts of interest regarding the publication of this paper.

\section{Founding}

Undergraduate Teaching Reform Project of Guangxi Higher Education (No: 2019JGA266), and Youjiang Medical University for Nationalities Research Project (No: yy2019bsky001).

\section{References}

Banks, S., Stanley, M. J., et al., (2019,58). Simulation-Based Interprofessional Education: A Nursing and Social Work Collaboration. Journal of Nursing Education, 2, 110-113. https://doi.org/10.3928/01484834-20190122-09

Cook, D. A., Aljamal, Y., et al., (2019,24). Supporting self-regulation in simulation-based education: a randomized experiment of practice schedules and goals. Advances in Health Sciences Education, 1. https://doi.org/10.1007/s10459-018-9860-z

Guo, W., Wang, W., et al., (2018,250). Design and Development of an Evaluation System for Managing Dry Skin Among Elderly Patients. Studies in Health Technology \& Informatics, 148.

Jennifer, O., Leann, H. T., et al., (2018,49). Integrative Review of Interprofessional Simulation in Nursing Practice. Journal of Continuing Education in Nursing, 2, 91-96. https://doi.org/10.3928/00220124-20180116-09

Johnson, R. B., Russo, F., et al., (2017). Causation in Mixed Methods Research: The Meeting of Philosophy, Science, and Practice. Journal of Mixed Methods Research, 155868981771961. https://doi.org/10.1177/1558689817719610

Lei, J., Zhao, Y., et al., (2020). Practice and exploration of teaching of small animal medical imaging technology in medical colleges. Medical Education Management.

Li-Mei, Zhao, et al., (2019). Investigation and analysis of attitudes and knowledge of aging among students in different majors. Frontiers of Nursing, 3, 211-215. https://doi.org/10.2478/FON-2019-0029

Lindsay, I., Nancy, B., et al., (2018,57). Development and Assessment of an Interprofessional Education Simulation to Promote Collaborative Learning and Practice. Journal of Nursing Education, 7, 426-429. https://doi.org/10.3928/01484834-20180618-08

Wei, X. J., Wang, Y., et al., (2018). Effect of psychological nursing in patients with breast cancer surgery. Chinese Journal of Cancer Prevention and Treatment.

Zhan, M., Shao-Li, H. U., et al., (2019,42). Application Research of Scenario Simulation Health Education in Intern Nurses. Chinese Journal of Health Education, 02, 91-96. 
Zhang, B., Zhang, Y., et al., (2018). Analysis on status quo of geriatric nursing core ability among practice nurses and its influence factors. Chongqing Medicine.

Zhu, Q., Wang, J., et al., (2018). The Application Effect of Operation Room Detail Nursing in Ensuring the Nursing Safety of the Operation Room. China Continuing Medical Education.

\section{Copyrights}

Copyright for this article is retained by the author(s), with first publication rights granted to the journal.

This is an open-access article distributed under the terms and conditions of the Creative Commons Attribution license which permits unrestricted use, distribution, and reproduction in any medium, provided the original work is properly cited. 